\title{
Exploration of Knowledge Engineering Paradigms for Smart Education: Techniques, Tools, Benefits and Challenges
}

\author{
ABDEL-BADEEH M. SALEM \\ Faculty of Computer and Information sciences \\ AinShams University \\ Abbassia 11566, St.El-Khalifa El-Mamoon, Cairo \\ EGYPT \\ abmsalem@yahoo.com absalem@,cis.asu.edu.eg http://staff.asu.edu.eg/Badeeh-Salem \\ ELENA V. MIKHALKINA \\ Faculty of Economics \\ Southern Federal University \\ M.Gorkogo str., 88, office 323, Rostov-on-Don, 344002 \\ RUSSIA \\ evmihalkina@sfedu.ru http://sfedu.ru/www/stat_pages22.show?p=UNI/s1/D\&params=(p_per_id=\%3E352) \\ ANASTASIA Y. NIKITAEVA \\ Faculty of Economics \\ Southern Federal University \\ M.Gorkogo str., 88, office 115, Rostov-on-Don, 344002 \\ RUSSIA \\ aunikitaeva@sfedu.ru http://sfedu.ru/www/stat pages22.show?p=UNI/s1/D\&params=(p_per id=\%3E378)
}

\begin{abstract}
Knowledge engineering paradigms (KEPs) deal with the development of intelligent systems in which reasoning and knowledge play pivotal role. Recently, KEPs receive increasing attention within the fields of smart education. Researchers have been used the knowledge engineering (KE) techniques, approaches and methodologies to develop a smart tutoring systems (STSs). The main characteristics of such systems are the ability of reasoning, inference and based on static and heuristic knowledge. On the other side, the convergence of artificial intelligence (AI), web science (WS) and data science (DS) is enabling the creation of a new generation of web-based smart systems for all educational and learning tasks. This paper discusses the KEPs techniques and tools for developing the smart educational and learning systems. Four most popular paradigms are discussed and analyzed namely; case-based reasoning, ontological engineering, data mining and intelligent agents. The main objective of this study is to determine and exploration the benefits and advantages of such computational paradigms to increase the effectiveness and enhancing the efficiency of the smart tutoring systems. Moreover, the paper addresses the challenges faced by the application developers and knowledge engineers in developing and deploying such systems. In addition to institutional and organizational aspects of smart educational technologies development and application.
\end{abstract}

Key-Words: Knowledge engineering and management, Artificial intelligence in education, Smart tutoring systems, Computational intelligence, Machine learning

Received: July 27, 2019. Revised: December 2, 2019. Accepted: January 13, 2020.

Published: January 27, 2020.

\section{Introduction}

Modern conditions of large-scale digitalization of society and the Fourth industrial revolution (Industry 4.0), manifested in the integration and interpenetration of digital and real physical systems [1], changing models of interaction between consumers and manufacturers, reducing the duration of innovation and industrial cycles, the emergence of new business models and models of social communications, put forward new requirements for education (educational services, educational technologies, competencies of students, etc.). The educational system, in order to be adequate to the needs and demands of modern society, requires the absorption, development and application of new 
models of education based on information and communication technologies and allowing the complex formation of a smart education system. That is, the education system is currently undergoing a period of digital transformation.

Smart education (SE) represents a collection of eservices that employ digital media and information and communication technologies (ICT) for supporting educational processes. SE is interdisciplinary area, encompassing many aspects of the educational technologies that cover instruction, training, teaching, learning, pedagogy, communication and collaboration. Moreover, the field of artificial intelligence in education (AID) has become the most challenging area in the last several years. It includes the disciplines: cognitive and social psychology, computer science, empirical psychology, intelligent software and knowledge engineering. The goal of the field is to deliver knowledge-based software which can be used in real teaching, learning and training situations.

Using AI concepts theories and techniques, new forms of smart educational software can be created that allow the computer to act as a smart tutor. Such AI-based smart tutoring system (STS) can adjust its tutorial to the student's knowledge, experience, strengths, and weaknesses. It may even be able to carry on a natural language dialogue. In addition, automatic generation of exercises and tests is an important feature of STS. Moreover, STS systems are complex to build and complex to maintain. This paper deals with the knowledge representation techniques and reasoning methodologies, namely: reasoning with rules, fuzzy logic, and case-based. Also, the paper addresses the challenges facing the designing of the STSs.

The rest of the paper is organized as follows: Section 2 is devoted to the literary review of scientific works on the considered problems. Section 3 describes the main features of smart tutoring systems. Section 4 presents some technical aspects about the knowledge representation and reasoning techniques which represents the backbones for any STS. Section 5 presents an overview about software intelligent authoring shells and tools. Section 6 discusses the most $\mathrm{KE}$ paradigms and techniques namely: case-based reasoning, ontological engineering, data mining and intelligent agents. Section 7 discusses the benefits of these techniques for developing STSs from educational point of view. Section 8 deals with institutional and organizational aspects of smart educational technologies development and application. The last section concludes the paper and illustrates the future work.

\section{Theoretical background and literature review}

The concept of smart education in scientific research is considered as the most relevant and important stage of digitalization of the educational sphere. In contrast to the previous stages (distance learning, e-learning, m-learning), smart education involves the provision of student-centered learning through interaction with learning materials using intelligent information systems, as well as the inclusion of non-formal learning opportunities and professional communities [2]. Smart education involves a comprehensive modernization of all educational processes, as well as methods and technologies used into this process. The term "smart" is often associated with the technological aspect and the emergence of smart technologies in education, including smart board, smart screens, smart course $[3,4]$, and a wide range of tools combined in the concept of "smart technologies" [5].

A research framework of smart education, including the definition and evolution of smart education, key features of smart learning environments, main smart educational technologies and opportunities of such technologies implementation in the educational sphere are proposed in a large number of papers over recent years [6,7]. From the technological point of view, smart education can be considered as technologyenhanced learning. Technologies can play role of media or tools for accessing learning content [8], communication and collaboration, construction, expression and evaluation [9]. With the development of smart technologies, learning platform got an opportunity to reacts to individual learner data and adapts educational resource based on cloud computing, artificial intelligent and learning analytics, and help to design of a demanded curricula using big data [10]. From the organization point of view, smart learning is considering as Selfdirected, Motivated, Adaptive, Resource-enriched, and Technology-embedded [11]. Smart educational systems have a high potential in the field of content customization and individualization of learning paths, provides students with an opportunity to implement their own leaning style [12]. Moreover, the educational process thanks to modern intelligent solutions can be carried out anytime, anywhere in the smart education context by using the intelligent 
devices [13]. In turn, from a managerial point of view, the development of smart technologies leads to the emergence of new educational strategies and models as well as development of smart and adaptive learning environment [14] in order to increase the quality of education. Different countries design various strategies of smart education development with the purpose to improve position in the global digital competitive environment [15].

Taking into account the variety and novelty of smart technologies, the establishment of an effective system of smart education requires an understanding of the features, functional purposes, advantages and challenges of various ITC solutions, as well as integrated consideration of technological, institutional, organizational and economic aspects of their implementation in educational sphere.

\section{Smart Tutoring Systems (STSs)}

STS is knowledge based software that act as an intelligent tutor used in real teaching. STS is also used in learning, and training situations. From the technical point of view, STS is composed of the following software components: (a) expert model, (b) student mode, (c) instructional module, (d) interface and (e) knowledge acquisition module. STS components are complex to build and complex to maintain .For more technical information, see [16]. Fig. 1 and Fig. 2 show the main features and benefits of the STSs from the educational point of view.

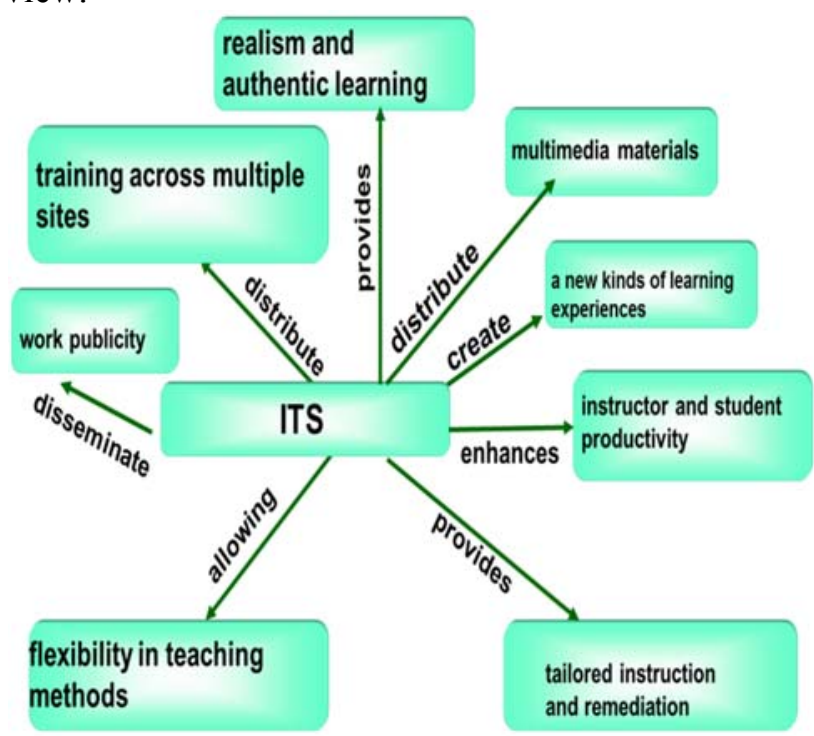

Fig 1. Main Features of STS

\section{Knowledge Representation and Reasoning Techniques for Smart Tutoring Systems}

From the knowledge engineering perspective, the main two components in developing an efficient and intelligent learning/educational system in any domain are the "knowledge base" and the "inference mechanism/engine".

- Adjust its tutorial to the student's knowledge, experience, strengths, and weaknesses.

- Use of pedagogical knowledge.

- Organize its knowledge in a lesson-oriented manner according to student models.

- Use of rhetorical knowledge (or rules) for natural language text generation.

- Addition of new knowledge is simple due to the structured object-oriented knowledge representation language.

- Generates exercises and test.

- Generates programs for illustration purposes.

- Evaluates student results for tests.

- Tireless teacher which adapts to the learners cognitive particularities and his individual progress.

- Based around a large amount of knowledge from the teaching domain.

- Learner's particularities and his progress are stored in the "student model".

- Carry on a natural language dialogues and explanations.

- Generate a highly structured collection of web pages.

\section{Fig 2. Benefits of STS}

Concerning the knowledge base, there are many knowledge representation and management techniques, e.g.; lists, trees, semantic networks, frames, scripts, production rules, cases, and ontologies. The key to the success of such systems is the selection of the appropriate technique that best fits the domain knowledge and the problem to be solved. That choice is depends on the experience of the knowledge engineer.

Regarding the inference engine, there are many methodologies and approaches of reasoning, e.g.: automated reasoning, case-based reasoning, commonsense reasoning, fuzzy reasoning, geometric reasoning, non-monotonic reasoning, model-based reasoning, probabilistic reasoning, causal reasoning, qualitative reasoning, spatial reasoning and temporal reasoning [17]. In fact these methodologies receive increasing attention within the community of AI-based smart tutoring systems industry $[18,19,20]$. Therefore, developing of STS for specific task face the knowledge-acquisition difficulty. So, efficiency of STS is based on the selection and determination of the appropriate 
knowledge representation techniques and reasoning methodologies.

\section{Intelligent Authoring Shells and Tools}

Intelligent authoring shells allow a course instructor to easily enter domain and other knowledge without requiring computer programming skills. The authoring shell automatically generates an ITS/IeLS focusing on the specified knowledge. It also facilitates the entry of examples/exercises, including problem descriptions, solutions steps, and explanations. The examples may be in the form of scenarios or simulations. It allows organized entry of the course principles and the integration of multimedia courseware (developed with well-known authoring tools) which includes descriptions of the principles or motivational passages. In addition to course knowledge, the instructor specifies pedagogical knowledge (how best to teach a particular student), and student modeling knowledge (how to assess actions and determine mastery).

The most common authoring shells are DIAG, RIDES-VIVIDS, XAIDA, REDEEM, EON, INTELLIGENT TUTOR, D3 TRAINER, CALAT, INTERBOOK, and PERSUADE [16]. Some tools were meant for select authors or students and others were designed for a wide set of authors. Some tools were designed to work with a limited area of domain expertise, and some were designed for a wide range of domains. Some tools had one main instructional strategy, but others had many. Each tool had their own way of representing the student's knowledge and understanding of the material being taught. Some tools generated instruction directly from domain knowledge. Some relied on pedagogical knowledge about the domain to create instruction. Some provided simulation environments for practice and exploration.

\section{Computational Intelligence Techniques for developing STS}

\subsection{Case Based Reasoning (CBR) Approach}

$\mathrm{CBR}$ is an analogical reasoning method provides both a methodology for problem solving and a cognitive model of people [21]. CBR means reasoning from experiences or "old cases" in an effort to solve problems, critique solutions, and explain anomalous situations. It is consistent with much that psychologist have observed in the natural problem solving that people do. People tend to be comfortable using CBR methodology for decision making, in dynamically changing situations and other situations were much is unknown and when solutions are not clear.

From knowledge engineering point of view, the "case" is a list of features that lead to a particular outcome. (e.g. The information on a patient history and the associated diagnosis). Fig 3 shows the contents of one "case" of a live cancer case.

Patient: 65-years old female not working, with nausea and vomiting.

Medical History: cancer head of pancreas .

Physical Exam: tender hepatomgaly liver, large amount of inflammatory about 3 liters, multiple liver pyogenic abscesses and large pancreatic head mass.

Laboratory Findings: total bilrubin 1.3 $\mathrm{mg} / \mathrm{dl}$, direct bilrubin $0.4 \mathrm{mg} / \mathrm{dl}$, sgot (ast) 28 IU/L, sgpt (alt) 26 IU/L.

Fig 3 Live cancer "case " description

Determining the appropriate case features is the main knowledge engineering task in developing case-based IeLS. This task involves defining the terminology of the domain and gathering representative cases of problem solving by the experts. Representation of cases can be in any of several forms (predicate, frames, scribes). From the computational point of view, CBR refers to a number of algorithms and techniques that can be used to record and index cases and then search them to identify the ones that might be useful in solving new cases when they are presented. In addition, there are techniques that can be used to modify earlier cases to better match new cases and other techniques to synthesize new cases when they are needed. CBR has already been applied in a number of different applications in many domains, e.g., medicine, industry, law, banking $[21,22,23]$.

Fig 4 shows the ideal components of the case. The "Case" composed of three major parts: (1) problem description, (2) solution, and (3) outcome. Problem description refers to the state of the world at the time the case is happening. Case solution refers to the stated or retrieved solution to the problem specified in the problem description. Case outcome defines the resulting state of the world when the solution was carried out. Depending on the case structure, the case can be used for a variety of purposes as shown in Fig 4.

In e-learning systems, the case can include: (a) A multi-media description of the problem, (b) A description of the correct actions to take including optimal and alternative steps, (c) A multi-media explanation of why these steps are correct, and (d) A list of methods to determine whether students 
correctly executed the steps. Determining the appropriate case features is the main knowledge engineering task in case-based AI software. This task involves defining the terminology of the domain and gathering representative cases of

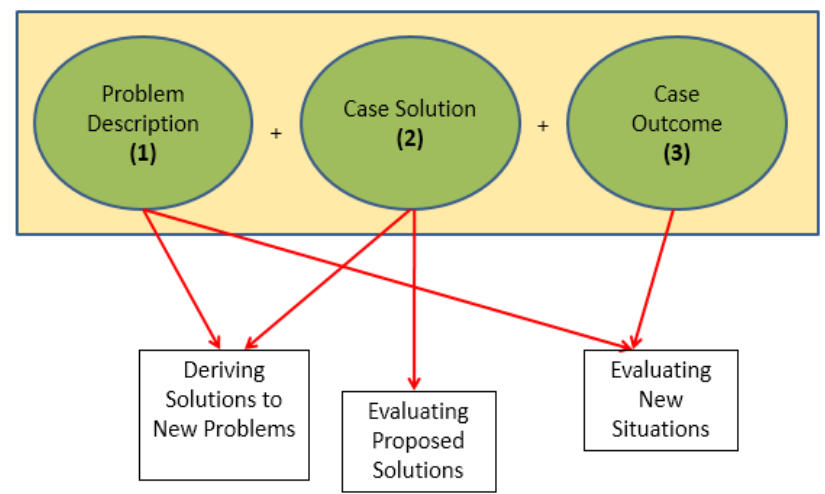

problem solving by the expert Representation of cased can be in any of several forms (predicate, frames, scribes).

\section{Fig 4. Depending on the case structure, the case} can be used for a variety of purposes

\subsection{Ontological Engineering approach}

The term "ontology" is inherited from philosophy, in which it is a branch of metaphysics concerned with the nature of being. The main objective of using ontologies is to share knowledge between computers or computers and human. Computers are capable to transmit and present the information stored in files with different formats, but they are not yet compatible to interpret them. To facilitate communication and intelligent processing of information, it is necessary that all actors of the digital space (computers and humans) have the same vocabulary. Ontologies are the foundation of cooperation and the semantical understanding between computers (running a lot of nonhomogenous software programs) and of the cooperation between computers and humans.

Most of the usages of ontologies in the field of computer science are related to knowledge based systems and intelligent systems. These types of ontologies include a small number of concepts and their main objective is to facilitate reasoning. For example, in multi-agent systems, the knowledge representation is accomplished through a basic ontology, privates ontologies and a knowledge base. Private ontologies of the agents are derived from the basic ontology. The names of the concepts used in private ontologies of the agents are unknown, but their definitions use terms from the basic ontology. During the last decade, increasing attention has been focused on ontologies [24]. At present, there are applications of ontologies with commercial, industrial, medical, academicals and research focuses [25, 26, 27, 28].

\subsection{Data Mining and Knowledge discovery approach}

Data mining methodology aims to extract useful knowledge and discover some hidden patterns from huge amount of databases which statistical approaches cannot discover. It is a multidisciplinary field of research includes: machine learning, databases, statistics, expert systems, visualization, high performance computing, rough sets, fuzzy logic, neural networks, and knowledge representation. Data mining techniques aim at providing intelligent computational methods for accumulating, changing and updating knowledge in intelligent systems, and in particular learning mechanisms that will help us to induce knowledge from information or data.

Knowledge discovery in databases (KDD) process involves the following processes; (a) using the database along with any required selection, preprocessing, sub-sampling, and transformations of it, (b) applying data mining methods (algorithms) to enumerate patterns from it, and (c) evaluating the products of data mining to identify the subset of the enumerated patterns deemed knowledge. The data mining components of the KDD process is concerned with the algorithmic means by which patterns are extracted and enumerated from data. The overall KDD process includes the evaluation and possible interpretation of the mined patterns to determine which patterns can be considered new knowledge. Data mining is supported by a host that captures the character of data in several different ways, e.g. clustring, classification, link analysis, sequence analysis, regression models, summarization, text mining, sequential pattern mining, association rules mining. In addition there are a lot of intelligent techniques to perform these tasks e.g. neural networks, support vector machines, decision trees, genetic algorithms, k-means and others. For more details we refer to the books [29, 30]. Table 1 shows the DM tasks and the appropriate techniques for each task.

Table 1: Data Mining Tasks and Techniques

\begin{tabular}{|l|l|}
\hline Data Mining Task & $\begin{array}{l}\text { Data Mining Algorithm \& } \\
\text { Technique }\end{array}$ \\
\hline Clustering & K-means \\
\hline
\end{tabular}




\begin{tabular}{|c|c|}
\hline Classification & $\begin{array}{l}\text { Support Vector Machines } \\
\text { Decision Trees ,Neural } \\
\text { Network, Rule induction , } \\
\text { Genetic Algorithm }\end{array}$ \\
\hline $\begin{array}{l}\text { Regression } \\
\text { prediction }\end{array}$ & $\begin{array}{l}\text { Support Vector } \\
\text { Decision Tresine, } \\
\text { induction, NN }\end{array}$ \\
\hline $\begin{array}{lr}\text { Association } & \text { and Link } \\
\text { Analysis } & \text { (finding } \\
\text { correlation } & \text { between } \\
\text { items in a dataset) }\end{array}$ & Association Rule Mining \\
\hline & \\
\hline
\end{tabular}

\subsection{Agent-based approaches for STSs}

Intelligent agents (IAs) are artificial entities that have several intelligent features, such as being autonomous, responding adequately to changes in their environment, persistently pursuing goals, flexible, robust, and social by interacting with other agents. IA mimics human interaction types, such as negotiation, coordination, cooperation, and teamwork. IAs are defined as computer systems situated in an environment and that are able to achieve their objectives by: (i) acting autonomously, i.e. by deciding themselves what to do, and (ii) being sociable, i.e. by interacting with other software agents. Agents are often seen as incarnations of various forms of $\mathrm{AI}$ including machine learning, reasoning and data mining. Research interests in agent systems are spanning various topics like modeling, design and development of advanced software systems that are appealing for a number of computer applications.

During the last decade, agent technologies were proposed to enhance e-learning systems across at least two dimensions: (i) agents as a modeling and design paradigm for advanced human-computer interaction and (ii) agents for smart functional decomposition of complex systems. Firstly, agents have been described as entities that exhibit several interesting properties that are very appealing for the modeling and design of advanced user interfaces encountered in e-learning systems: teachers, tutors and students. Secondly, generic agent types proven to be effective for the appropriate functional decomposition of e-learning systems. Dynamic and interoperability characteristics of agents are very suitable for supporting maintainability and extensibility of e-learning systems.

\section{Benefits of intelligent techniques smart tutoring systems}

This section discusses the benefits of the previous techniques for STS

\subsection{Benefits of CBR Approach to STSs}

The idea of CBR is becoming popular in developing intelligent eLearning/tutoring systems because it automates applications that are based on precedent or that contain incomplete causal models. Research reveals that students learn best when they are presented with examples of problem-solving knowledge and are then required applying the knowledge to real situations. The case-memory of examples and exercises capture realistic problemsolving situations and presents them to the students as virtual simulations.

On the other hand, there are several benefits where students/learners should be able to perform better using CBR methodology, e.g.,

- With more cases available, students will be able to recognize more situations and the solutions that go with these cases include failure cases, students will be able to benefit from the failures of others.

- Retrieval cases will allow students to better recognize what is important in a new situation. Cases indexed by experts would recall and will show the student ways of looking at a problem that he might not have the expertise for without the system.

- Student will have access to obscure cases that they otherwise would not able to make use of. These obscure cases can help with any of the tasks previously listed.

- During a training period CBR system provides the student with a model of the way decision making ought to be done, for example, what things ought to be considered and provides them with concrete examples on which to hang their more abstract knowledge.

For tasks where there is much to remember, CBR systems can augment the memories of even educators. Also, both educators and students tend to focus on too few possibilities when reasoning analogically or to focus on the wrong cases.

\subsection{Benefits of Ontology Paradigm to STSs}

Ontologies' usage in educational systems may be approached from various points of view: as a common vocabulary for multi-agent system, as a chain between heterogeneous educational systems, ontologies for pedagogical resources sharing or for sharing data and ontologies used to mediate the search of the learning materials on the internet [31]. 
The abstract specification of a system is composed of functional interconnected elements. These elements communicate using an interface and a common vocabulary. The online instructional process can be implemented successfully using artificial Intelligence techniques. Sophistical software programs with the following features give the intelligence of the machine: adaptability, flexibility. Learning capacity, reactive capacity, autonomy, and collaboration and understanding capacity. This approach enables to solve the complexity and the incertitude of the instructional systems. An intelligent learning system based on a multi-agent approach consists in a set of intelligent agents, which have to communicate. They collaborate through messages. Software agents can understand and interpret the messages due to a common ontology or the interoperability of the private ontologies.

\subsection{Benefits of data mining paradigm to STSs}

This section presents the applications of some of the data mining methods and tasks in smart education and learning. Further details and other applications can be found in [19].

\subsubsection{Information Visualization in STS}

Information visualization (IV) can be used to graphically render complex, multidimensional student tracking data collected by web-based learning/educational systems. The IV in e-learning can be used in the following educational tasks; admitted questions, complementary assignments, exam scores, etc. Moreover visualization tools (e.g.,GISMO CourseVis) enable instructors to manipulate the graphical representations generated, which allow them to gain an understanding of their learners and become aware of what is happening in distance classes.

\subsubsection{Clustering in STS}

Clustering approach has been used in smart education and learning for the following tasks:

- Finding clusters of students with similar learning characteristics and to promote group-based collaborative learning as well as to provide incremental learner diagnosis.

- Discovering patterns reflecting user behaviors and for collaboration management to characterize similar behavior groups in unstructured collaboration spaces.

- Grouping students and personalized itineraries for courses based on learning objects.
- Grouping students in order to give them differentiated guiding according to their skills and other characteristics.

Grouping tests and questions into related groups based on the data in the score matrix.

\section{Institutional and Organizational Aspects of Smart Educational Technologies Development and Application}

At the same time, the realization of all the advantages and areas of application of smart educational technologies is associated not only with engineering and technological aspects, but also with institutional, organizational and economic issues of their development and integration into the existing educational environment, as well as a comprehensive innovative modernization of the educational environment.

From an institutional perspective, it is necessary to provide a legitimate basis, establish strategies and development programs, create favorable institutional environment, and establish rules and procedures for the designing and using of innovative intellectual educational technologies. The point is that it is important to institutionalize smart education.

This involves making a set of decisions:

- at the country level, covering: the inclusion of digitalization in a broad sense and intellectual technologies in particular in the scientific and technological priorities of the national economic system; support for educational programs in the ICT sphere, the promotion of digitalization and intellectualization of educational processes; the creation of favorable conditions for the development of networks and partnerships between educational institutions, between educational institutions with state authorities and industrial partners;

- at the regional and sectoral level: establishment of a regulatory framework and institutional conditions for the accumulation, exchange and use of adequate information for creation of content for smart educational technologies, the development of expert platforms and institutions for the designing of smart education;

- at the level of educational institutions: the rules and procedures for the design and incorporation of smart technologies into the educational process and their integrated .

This will ensure the widespread introduction of smart technologies in the educational process and will lead to positive synergetic and multiplicative effects. 
In turn, speaking about the development of smart education in the economic context, it is important to note the need for appropriate resources. This requires multi-channel funding for smart educational technologies (in terms of designing, development, dissemination and implementation) from both government agencies and educational institutions themselves and their partners in the real sector and the ICT sector of the economy. Equally important is the promotion of demand for appropriate technological innovations in education.

Finally, we cannot leave out of the consideration the organizational and managerial aspect, which is revealed in the range of questions from the creation of a motivational mechanism for employees to develop and implement smart educational technologies that are most applicable in a particular field of knowledge for solving certain tasks to the modernization of the entire model of strategic development of universities based on the potential of smart digital solutions.

\section{Conclusions and Future Work}

In this concluding part, we identify some of the major open problems that must be addressed to ensure the success of developing robust intelligent e-learning systems. In summary, the development of intelligent e-Learning/educational systems is a very difficult and complex process that raises a lot of technological and research challenges that have to be addressed in an interdisciplinary way. Today's the fusion of computational intelligence and machine learning techniques with the knowledge acquisition techniques solves many of the technical problems and difficulties in designing new generation of intelligent e-Learning/educational systems. Further research however is needed to convergence the knowledge engineering, artificial intelligence, machine learning, educational technology with the web science. Such convergence will create a new generation of web-based intelligent e-learning and tutoring systems. The web based of such systems can enhance the online education/ learning/training processes through the web. On the other hand, Intelligent agents technology, as a modern version of AI ,where knowledge representation is enhanced with learning and social interaction. In the current environment of global wired and wireless networks, IAs may play the role of a universal carrier of distributed AI. So, the integration of software agents approaches and educational technologies is beneficial for designing efficient, robust and intelligent e-learning systems. In addition, ensuring the success of such systems to the cloud is an important challenge.

\section{References:}

[1] Schwab K. The Fourth Industrial Revolution. World Economic Forum. 2016

[2] Dneprovskaya N. V. Knowledge management system as a basis for smart learning. Open education. $\mathrm{V}$. $22 . \quad$ № 4. 2018.https://cyberleninka.ru/article/n/ponyatiyn ye-osnovy-kontseptsii-smart-obrazovaniya

[3] Merzon E. E., Ibatullin R. R. Architecture of smart learning courses in higher education. 2016 IEEE 10th International Conference on Application of Information and Communication Technologies (AICT), Baku. 2016. pp. 1-5.

[4] Gasparian M.S., Lebedev S.A., Tel'nov YU.F. Inzhiniring obrazovatel'nykh program na osnove primeneniya intellektual'nykh tekhnologiy. Otkrytoye obrazovaniye. No. 1. 2017. P. 14-19. https://doi.org/10.21686/18184243-2017-1-14-19 (In Russ.)

[5] Zhu Z., Yu M., Riezebos P. A research framework of smart education, Smart Learning Environments. Vol. 3 (4). 2016.

[6] Huang R., Yang J., Hu Y. From digital to smart: the evolution and trends of learning environment. Open Educ. Res. 1, 2012, pp. 7584.

[7] Hwang G.J. Definition, framework and research issues of smart learning environmentsa context-aware ubiquitous learning perspective. Smart Learning Environments 1(1), 2014, pp.1-14

[8] Daniel J. Making sense of MOOCs: musings in a maze of myth, paradox and possibility. $J$. Interact. Media Educ. 3, 2012, Art-18.

[9] Zhu Z., Yu M., Riezebos P. A research framework of smart education, Smart Learning Environments. Vol. 3 (4). 2016.

[10] New Media Consortium, The NMC Horizon Report: 2015 Higher Education Edition, 2015, pp. $1-50$

[11] Kim T., Cho J.Y., Lee B.G. Evolution to Smart Learning in Public Education: A Case Study of Korean Public Education. In: Ley T., Ruohonen M., Laanpere M., Tatnall A. (eds) Open and Social Technologies for Networked Learning. OST 2012. IFIP Advances in Information and Communication Technology, vol 395. 2013. Springer, Berlin, Heidelberg.

[12] Bajaj R., Sharma V. Smart Education with artificial intelligence based determination of learning styles. International Conference on 
Computational Intelligence and Data Science (ICCIDS 2018). Procedia Computer Science 132, 2018, pp. 834-842.

[13] Lina J., Puc H., Li Y., Lian J. Intelligent Recommendation System for Course Selection in Smart Education. 2017 International Conference on Identification, Information and Knowledge in the Internet of Things. Procedia Computer Science 129, 2018. pp. 449-453

[14] Janati S.L., Maach A., Ghanamia D.E. SMART Education Framework for Adaptation Content Presentation. The First International Conference On Intelligent Computing in Data Sciences. Procedia Computer Science 127, 2018, pp. 436-443.

[15] Aldulaimi M.H., Kadhim T. A. and Alfaras M. S. Towards smart learning environments in Iraqi schools - existing infrastructure and challenges. International Journal of Civil Engineering and Technology (IJCIET). Volume 9, Issue 11, November 2018, pp. 1939-1951

[16] Greer J. Proceedings of AI-ED 95, World Conference on Artificial Intelligence in Education, Assocaition for Advancement of Computing in Education (AACE), 1995.

[17] Pawlak Z. Rough Sets: Theoretical Aspects of Reasoning about Data, Kluwer Academic Publishers, Dordrecht, 1991.

[18] Abdel-Badeeh M. Salem, "Intellectual ELearning Systems", Proc. Of the Annual International Conference on"Virtual and Augmented Reality in Education" (VARE 2011) (combined with EEA and Norwegien Finansial Instruments project practical conference"VR/AR Applications in Training"), Vidzeme University of Applied Sciences, Valmiera, Latvia, PP 16-23, March 2011.

[19] Abdel-Badeeh M. Salem, Data Mining Technology in e-Learning, Proceedings of 6th International Conference on Emerging elearning Technologies and Applications, Information and Communication Technologies in Learning, (ICETA2008), Stara Lesna,The High Tatras,Slovakia,2008.

[20] Abdel-Badeeh M. Salem, The Role of Artificial Intelligence Technology in Education, Proceedings of 5th International Conference on Emerging e-learning Technologies and Applications, Information and Communication Technologies in Learning, ICETA, The High Tatras, Slovakia, PP 1-9, 2007.

[21] Kolonder J. Case-Based Reasoning, Morgan Kaufmann, 1993.

[22] Abdel-Badeeh M. Salem, Michael Gr. Voskoglou, Applications of the CBR
Methodology to Medicine, Egyptian Computer Science Journal ,Vol.37, No.7, 2013, pp.68-77.

[23] Abdrabou E. A. M. \& Salem, A. B. A Breast Cancer Classifier based on a Combination of Case-Based Reasoning and Ontology Approach", Proc. of 2nd International Multiconference on Computer Science and Information Technology. IMCSIT 2010, Wisła, Poland, 2010.

[24] Tankelevciene L., Damasevicius R. Characteristics for Domain Ontologies for Web Based Learning and their Application for Quality Evaluation, Informatics in Education, Vol. 8 No 1, 2009. pp. 131-152,

[25] Abdel-Badeeh M. Salem, Ontological Engineering in e-Learning, Proceedings of 8th International Conference on Emerging elearning Technologies and Applications, Information and Communication Technologies in Learning, (ICETA2010), Stara Lesna, The High Tatras,Slovakia, 2010.

[26] Abdel-Badeeh M.Salem, Marco Alfonse. "Ontological Engineering in Medicine". Medical Informatics Workshop, Third International Conference on Intelligent Computing and Information Systems, Cairo, Egypt, PP 59-74, 2007.

[27] M.VijayaKumar, Abdel-Badeeh M. Salem, S.Karthick and Hanumanthappa, " Mining Based Crime Classification for Detecting Crime Hot Spot and Cold Spot", Egyptian Computer Science Journal, Vol.37, No.4, 2013. pp.1-13.

[28] Su X. and Ilebrekke L. A Comparative Study of Ontology Languages and Tools, Proceedings of the 14th Conf. on Advanced Information Systems Engineering (CAiSE'02), Toronto, Canada, 2002.

[29] Cios K. J., Pedrycz W. and Swiniarski R. W. Data Mining Methods for Knowledge Discovery. Kluwer 1998.

[30] Witten I. H. and Frank E. Data Mining Practical Machine Learning Tools and Techniques. 2nd ed, Elsevier, 2005.

[31] Sarma Cakula, Abdel-Badeeh M. Salem, "ONTOLOGY-BASED COLLABORATIVE MODEL FOR E-Learning ", Proc.of the Annual Int Conf on"Virtual and Augmented Reality in Education" (VARE 2011) (combined with EEA and Norwegien Finansial Instruments project practical conference"VR/AR Applications in Training"), Vidzeme University of Applied Sciences, Valmiera, Latvia,PP 98-105, 18 March 2011. 